\section{Whale numbers}

SIR - An advertisement placed by MJ Research Inc. in Nature for 20 April featured an item headed "Humpback whale still hunted, mtDNA shows". The paper referenced, by Baker and Palumbi, claimed only to have identified one sample that matched both Atlantic minke whale and humpback.

It is critical to Baker and Palumbi's conclusions that whale meat continues to be illegally imported into Japan that whale meat may be stored up to 10 years at $-20^{\circ} \mathrm{C}$. The meat of all species referred to by Baker and Palumbi was legally imported into Japan until 1991.

The Baker and Palumbi paper has subsequently been seriously questioned at an international symposium on marine mammal genetics (La Jolla, September 1994). The assessment, by Nobuyuki Yagi of the Japanese Fisheries Agency, included the important observation (omitted by Baker and Palumbi) that a large number of toothed whales are legally sold in the Japanese market, yet none of these DNA type sequences was available to the investigators for comparison with the samples they analysed.

Potential contamination of the samples is also of scientific concern; the meat for analysis was obtained from retail stores and subjected to various processes (including marination) before being analysed. Such treatment may explain the mtDNA sequence identified as being midway between a minke and humpback, and another anomalous sequence claimed to be "intermediate between a sperm whale and a harbour porpoise". A more likely explanation for the latter sequence could be that 18 or more species of toothed whale (whose DNA profiles were unavailable to the researchers) were legally taken or stranded in Japan in 1993, and sold legally in food stores.

\section{Milton Freeman}

Department of Anthropology,

13-15 HM Tory Building,

University of Alberta,

Edmonton, Alberta, Canada T6G $2 \mathrm{H} 4$

\section{Site for disposal}

SIR - There are a number of errors in the article "Nuclear storage decision postponed" (Nature 375, 174; 1995), not the least of which is the headline. It is almost inconceivable that anyone reading the Department of Environment announcement could conclude that it advocated postponement "until at least the latter half of the next century".

Instead, the government has said that Nirex should "proceed without any unnecessary delay, subject to meeting the necessary planning and regulatory requirements". When announcing preliminary conclusions to the Review of Radioactive Waste Management Policy, Mr John Gummer, the Secretary of State for the Environment said: "The Review also looked at a fifty year delay and concluded that the balance of argument was against any such delay. The Government therefore believes that the repository should be constructed as soon as reasonably practicable, once a suitable site has been found."

The current target for first emplacement of waste is around 2010, which would imply that construction must begin in the first half of the decade. In fact, 2060 is the estimated date of repository closure, not the earliest date of the commencement of construction as stated in your article.

For the record, the current phase of the company's search for a deep disposal site commenced in 1987. Site investigations at Sellafield commenced in 1989. Nirex has so far spent some $£ 300$ million, much of this on scientific research, in its search for a suitable site.

Tom Curtin

(Head of Corporate Communications)

United Kingdom Nirex Limited,

Curie Avenue,

Hanwell, Didcot,

Oxfordshire OX11 ORH, UK

\section{Forced evolution}

SIR - Your report on the Biotechnology and Biological Sciences Research Council workshop on forced evolution ${ }^{1}$ does not mention whether Captain Lemuel Gulliver was a participant, nor whether the Grand Academy of Lagado was invited to send a representative.

Readers of Gulliver's Travels ${ }^{2}$ will recall the genetic algorithm employed by the Professor in Speculative Learning and his 40 graduate students according to which, by the artificial selection of words randomly generated by tossing wooden blocks in a frame, "the most ignorant person may write books without the least assistance from genius or study".

"Six hours a day the young students were employed in this labour, and the professor showed me several volumes in large folio already collected, of broken sentences, which he intended to piece together, and out of those rich materials to give the world a complete body of all arts and sciences; which might however still be improved, and much expedited, if the public would raise a fund for making and employing five hundred such frames in Lagado, and oblige the managers to contribute in common their several collections."

It is not know whether the professor's grant application succeeded, but it is known that Charles Darwin read Gulliver's Travels at Maer Hall between June and November 1840 (ref. 3).

\section{A. W. F. Edwards}

Gonville and Caius College,

Cambridge CB2 1TA, UK

1. Brookfield, J. F. Y. Nature 375, 449 (1995).

2. Swift, J. Gulliver's Travels (1726).

3. Burkhardt, F. \& Smith, S. (eds) The Correspondence of Charles Darwin 4 (Cambridge Univ. Press, 1988).

\section{Authors scorned}

SIR - Keith Frayn's objections to the unreasonable policies of certain scientific publishers (Nature 375, 100; 1995) are long overdue. As a research editorial assistant, I have seen numerous examples of everything Frayn describes, along with many examples of slipshod project planning. In one instance, it was more than two years before my boss received the page proofs of a book chapter he had been invited to submit. They arrived by regular mail — on a Friday — with an "urgent" memo stipulating that corrections be returned by overnight courier within 48 hours in order to avoid publication delays. Although we met this deadline, it was almost another year before the book was finally published. By that time, the entire volume was sorely out of date and virtually useless to readers intent upon keeping up with current research. Louis Delpino

Department of Pathology,

University of Pennsylvania,

Philadelphia,

Pennsylvania 19104-6082, USA

\section{History of Xerox}

SIR - In the leading article "Cutting off the sap to US research" (Nature 375, 263; 1995), it was stated that it would be impossible to trace the research and funding that led to the Xerox photocopier. Although the origin and development of the Xerox process is a mystery to almost everyone, it is known to a very few.

The process was invented by Chester Carlson, a graduate in the 1920 s of the California Institute of Technology. The research leading to the present-day Xerox photocopier is as follows: research by Carlson, then Battelle Research Institute, then the Haloid Corporation which then transformed itself into the Xerox Corporation and refined the process.

It is ironic that Carlson, despite bestowing a great boon on society, remains almost completely unknown. He is the epitome of the Inventor Ignotus.

\section{George W. Housner}

California Institute of Technology,

Division of Engineering

and Applied Science,

Mail Code 104-44,

Pasadena, California 91125, USA 